\title{
A Multi-Agent Intelligent Learning System: An Application with a Pedagogical Agent and Learning Objects
}

\author{
Sánchez-Guerrero Lourdes ${ }^{1}$, Laureano-Cruces Ana Lilia ${ }^{1,2,3}$, Mora-Torres Martha ${ }^{3}$, \\ Ramírez-Rodríguez Javier ${ }^{1,2}$, Silva-López Rafaela Blanca ${ }^{1}$ \\ ${ }^{1}$ Departamento de Sistemas, Universidad Autónoma Metropolitana Azcapotzalco, \\ Distrito Federal, México \\ ${ }^{2}$ Laboratoire Informatique d'Avignon, Université d'Avignon et des Pays de Vaucluse, \\ Avignon, France \\ ${ }^{3}$ Posgrado en Ciencia e Ingeniería de la Computación, Universidad Nacional Autónoma de México, \\ Distrito Federal, México \\ Email: lsg@correo.azc.uam.mx, clc@correo.azc.uam.mx, jararo@correo.azc.uam.mx, \\ rbsl@correo.azc.uam.mx, kabhun@yahoo.com.mx
}

Received May 29 $9^{\text {th }}$ 2013; revised June $29^{\text {th }}, 2013$; accepted July $6^{\text {th }}, 2013$

Copyright (C) 2013 Sánchez-Guerrero Lourdes et al. This is an open access article distributed under the Creative Commons Attribution License, which permits unrestricted use, distribution, and reproduction in any medium, provided the original work is properly cited.

\begin{abstract}
This article describes the analysis, design and development of an Intelligent Learning System (ILS). The design of the ILS is based on a multi-agent architecture. This architecture includes reactive agents which represent the expertise of each of the necessary sub-skills in learning the application domain, which in the study case is structured programming. The ILS utilizes artificial intelligence techniques to implement the teaching-learning process using an inference engine based on a general didactic model. As a result, this system is termed as Intelligent Learning System with Learning Objects (ProgEst). ProgEst is carried out with the objective of providing the user with self-regulated learning strategies in addition to the knowledge of a determined domain. The case study includes situations related to: learning styles, knowledge domain (errors made) and affective-motivational state. The assessments shall determine: 1 ) what is to be explained, 2) level of detail and timing, 3) how and when to interrupt the student, and 4) the information to provide during the interaction.
\end{abstract}

Keywords: Intelligent Learning System; Educational Objective; Learning Object

\section{Introduction}

The information and communication technologies of today have evolved rapidly, affecting their application in distinct disciplines. One of the sciences in which they are more frequently being applied is education. At present, a wide variety of electronic media are utilized to send or receive support materials, for the purposes of Distance Education (DE), which has given rise to the e-learning modality. This term refers to the use of new information and communication technologies with a learning objective which involves: 1 ) the way of organizing educational content; 2) the mode of accessing them; and 3) their use in the teaching and learning process. Intelligent learning system (ILS) with learning objects ( $L O)$ (ProgEst) was designed to support students in understanding and learning the skill of programming.

The (LO) model offers a way to build educational content by composition from parts of elements which are located in the lower levels of learning.

According to Chan-Núñez, Galeana-de la, Ramírez-Montoya (2006), one of the reasons for which the notion of the LO has gained such strength in the field of information and communications technology (ICT)-based education is the fact that it can be considered as a bridge concept between: education, commu- nication, design and computer sciences, among others.

Learning environments are changing rapidly, implying new scenarios that pose technical and pedagogical challenges which higher education institutions must consider in their educational model, and professors, students and support staff must quickly adapt to the use of these new environments. The primary objective of this work lies in combining the new technologies with artificial intelligence (AI) and LO. The following elements were analyzed for the purpose of accomplishing this objective: 1) the pedagogical model used in the didactic materials which are developed, 2) the publication for which the material is created, and 3) the use of LO.

The ILS bases its teaching and learning process in an inference engine inspired by the human tutorial process and is comprised of the following elements: 1) interest, 2) desire, 3) help, 4) cognitive and operational strategies, 5) interruption, 6) quitting, 7) learning, 8) idle time, 9) error 10) student's perceived tendencies (Laureano-Cruces, Mora-Torres, Ramirez-Rodriguez, de Arriaga-Gómez, \& Escarela-Perez, 2010a). These elements are connected in a causal matrix which allows us to see the interconnection of each element with the others. In addition to these elements, learning style is included, which will have a direct impact on the interface and the internal motivation of the object of study. All of these allow selection of the operational 
strategies at the appropriate time. The inference engine is represented by extensive cognitive maps, one of the AI techniques used for representation of knowledge with uncertainty and design of the inference engine. The latter is not included in the development of this project (For more information, see Laureano-Cruces, Sánchez-Guerrero, Ramirez-Rodriguez, \& MoraTorres, 2008a; Mora-Torres, Laureano-Cruces, \& Velasco-Santos, 2011).

On the other hand, the curriculum is designed using a genetic graph, which is based on a multi-agent architecture, implying three expert agents, each one in a sub-domain (Laureano-Cruces \& de Arriaga-Gómez, 1998; Laureano-Cruces \& de Arriaga-Gómez, 2000; Sanchez-Guerrero, Laureano-Cruces, MoraTorres, \& Ramírez-Rodríguez, 2010). The sub-domains are represented by instructional objectives. The aforementioned permits the elaboration of a teaching- learning process based on scenarios linked to each one of these sub-domains, and thus allows for detailed error management. For further details, see Reilly \& Lewis (1991).

The structured programming content was organized based on the LO model, as these offer a way of building educational content by composition based on parts of elements which are located in the lower levels. Likewise, it is a way to search for objects and content, locate, recover and integrate them through a collection of specifications and standards for web based e-learning, or SCORM (Shareable Content Object Reference Model), for their cataloguing, requisition, export, transport and import. Finally, it offers the possibility to build a personalized selection of educational content for each student and moment which offers the optimal context for his or her learning. For greater detail see references (Muñoz-Arteaga, Osorio-Urrutia, Álvarez Rodríguez, \& Cardona-Salas, 2008). Chapter 2 explains how the ProgEst system is integrated, chapter 3 explains the example of the use of ProgEst and, finally, we find the conclusions.

\section{ProgEst System}

ILS's pose the learning process as cooperation between an intelligent system and humans (Laureano-Cruces, 2000a; Laureano-Cruces \& de Arriaga-Gómez, 2000b). The tutor, based on the evaluation of the user's performance, is found within a constant decision-making process for the purpose of selecting the most appropriate teaching strategy. These strategies are elaborated based on the perception of the user's performance taking a series of evidence as parameters, such as: errors made, learning style, knowledge domain and affective-motivational state, among others (Pintrich, Smith, García, \& Mckeachie, 1991). These assessments determine: what is to be explained, the level of detail and timing, when to interrupt the student and which information to provide during the interaction.

An ILS has been designed and implemented together with the learning objects, called ProgEst. An inference engine was utilized to achieve this, based on a general didactic tutor (Laureano-Cruces, Teran-Gilmore, \& Rodriguez-Aguilar, 2005; Laureano-Cruces, Mora-Torres, Ramírez-Rodríguez, \& de ArriagaGómez, 2011). This is linked to the case study tutor module and to the perceived user performance (student model). The user performance is represented by the student model. The relationship between the tutor module and the student model permits creation of the distinct didactic strategies.

In the ProgEst system, the cognitive didactic is designed in accordance with the instructional objectives (IO), which represent the cognitive sub-skills and abilities the professor (in this case, the tutor module) wants to convey to the student (Laureano-Cruces et al., 2000b; Laureano-Cruces, Teran-Gilmore, De Arriaga Gomez, \& El Alami, 2003; Laureano-Cruces, et al., 2005). These abilities are activated together with operational didactics (Figure 1).

\section{Design of the Agents}

The mental model generally implies use of the distinct control structures. This point is very important and is part of the detailed logic stage of each module (descending modular programming and structured programming). Taking this into account and based on the instructional objectives (defined in Section 3.1), three agents are included: 1) types of data, variables and constants, 2) control structures: (sequence, iteration: conditional (during and repeated) and non-conditional (arithmetic progression), selection: simple (if, then, except) and multiple (case dependent)) and 3) abstractions: (procedures, functions)

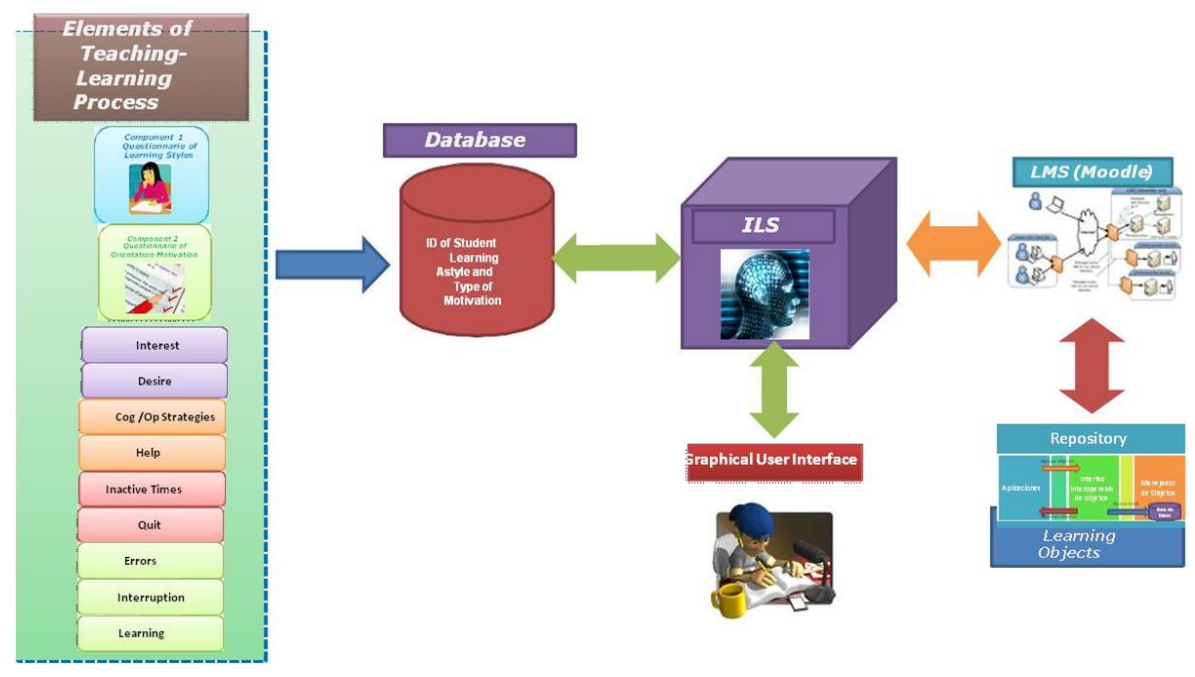

Figure 1.

Intelligent learning system (ILS) with learning objects (ProgEst). 
(Figure 2).

The teaching-learning process is based on the previous Genetical Graph (Figure 2), the nodes of which represent the instructional objectives. These objectives are immersed in a multiagent structure (Laureano-Cruces et al., 2000b).

\section{Multiagent Model}

The MultiAgent structure and its anatomy are made up of three parts: a presentation (P), an abstraction (A) and a dialogue control (DC). The presentation is the part of the agent which is viewed by the world and is related to a presentation technique.

\section{Didactical Design}

The abstraction represents the local status of the agent. It is the part which contains the conceptual objectives for accessing the domain and is where the competence of the agent is implemented. The coordination between the abstraction and the presentation and coordination with other agents is carried out, if necessary, in the dialogue control. It is worth mentioning that agents may exist which contain solely the presentation part or the abstraction part or neither.

The agents performance is divided into two subagents, the first being the diagnostic, of which the objective is to address the environment (the student's progress). It acquires evidence
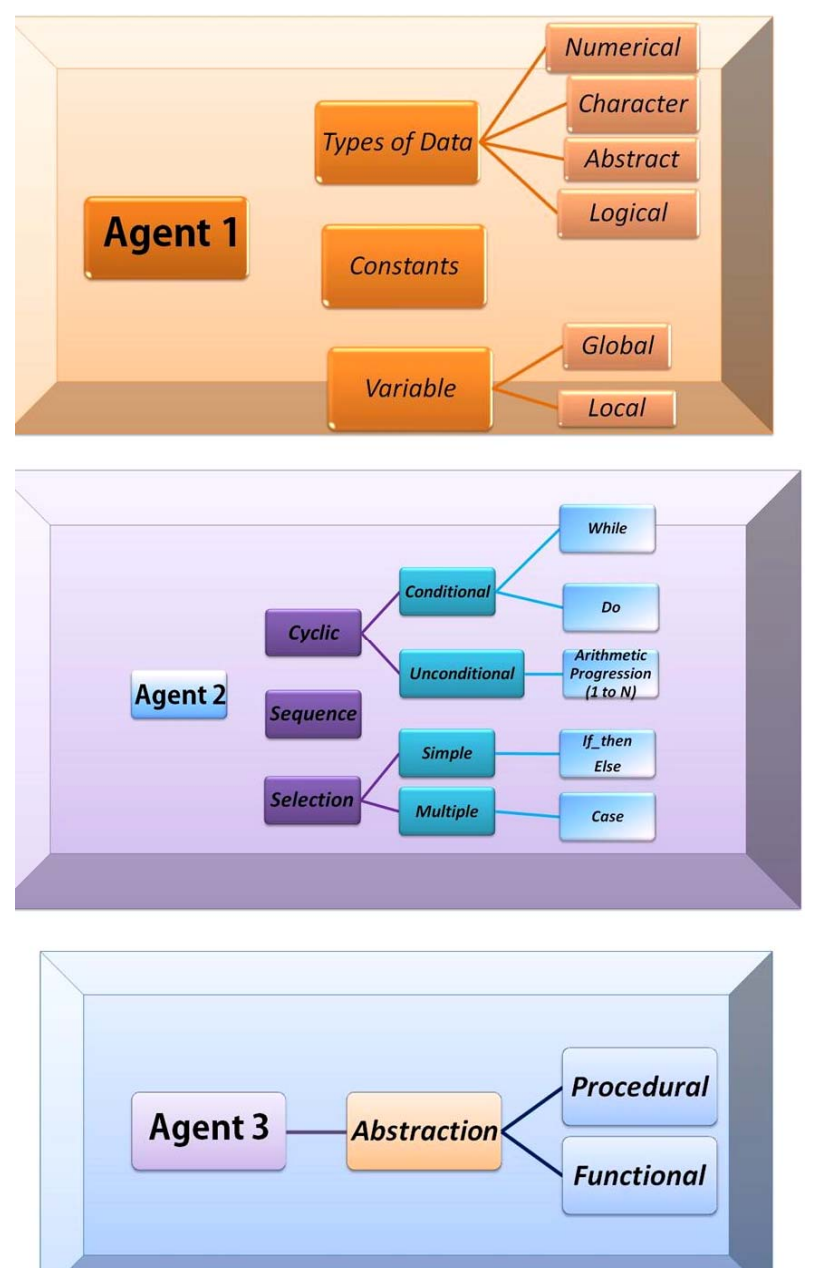

Figure 2.

Domain of each agent. of the agent's perceptual abilities using the obtained information in order to know if the student employs, does not employ or incorrectly employs the skill which is monitored and controlled exclusively by said agent. Based on the findings it detects the committed error(s), thus activating the second subagent, represented by a MicroWorld with the mission of creating an environment which assists the student in clarifying his or her doubts. The aforementioned is carried out by means of didactical methods which guide the intervention throughout completion of the process, reestablishing the student in the principal environment where the error occurred.

In ProgEst, the intervention of the MicroWorld consists of presenting an explanation of the subject followed by complete examples which show the correct use of the skill. The ProgEst system architecture is a multi-agent architecture and its anatomy is composed of three independent agents: 1) types of data, variables and constants, 2) control structures and 3) abstractions. The task which they develop is hierarchical, resolving the problem of intervention during development of the session (Laureano-Cruces et al., 1998; Laureano-Cruces et al., 2000b; Sanchez-Guerrero, Laureano-Cruces, Mora-Torres, \& RamirezRodriguez, 2011). The agents review the task in determined critical points (identified by the expert) in an organized manner due to the aforementioned hierarchy. If any of them identifies a failure, its internal mechanism is activated. For greater detail, consult (Sanchez-Guerrero, Laureano-Cruces, Mora-Torres, \& Ramirez-Rodriguez, 2009) (Figures 2 and 3). ProgEst has the capacity to ask for help within the scenario, permitting the content of the respective topic to be shown prior to asking the $\mathrm{Mi}$ croWorld. This is due to the trainer approach of our ILS. Errors are classified as: mild, serious and fatal. This classification is developed based on the authors' experience. According to the multi-agent architecture with dynamic intervention proposed by Laureano-Cruces (Laureano-Cruces et al., 1998; Laureano-Cruces, 2000a; Laureano-Cruces et al., 2000b), specialists are created which act as reactive agents that are activated in the moment an error which corresponds to their expertise is made (Table 2). For greater detail, see Reilly et al. (1991).

\section{Interface}

We designed a pedagogical agent that evokes, through facial expressions, emotions necessary in implementing cognitiveaffective strategies in the environment of the teaching-learning process. In Figures 4-6, some of them are shown. Some other expressions are also shown related with interest and sympathy, useful for interaction between pedagogical agent (ILS) and the user.

\section{ProgEst Application Example}

In this section, we will present an example of the application of the ProgEst system, utilizing the evaluation of the Data Types scenario as a case study, for the purpose of explaining the execution of the ProgEst system step by step.

It is important to comment that the system is implemented in the Moodle (Learning Management System Moodle, obtained of: http://moodle.org) learning management system (LMS) platform, and integrated in the ProgEst system architecture, see (Figure 1), and thus the scenarios and management of the learning objects are presented. Similarly, the ILS in the interface design is connected with the learning styles by means 


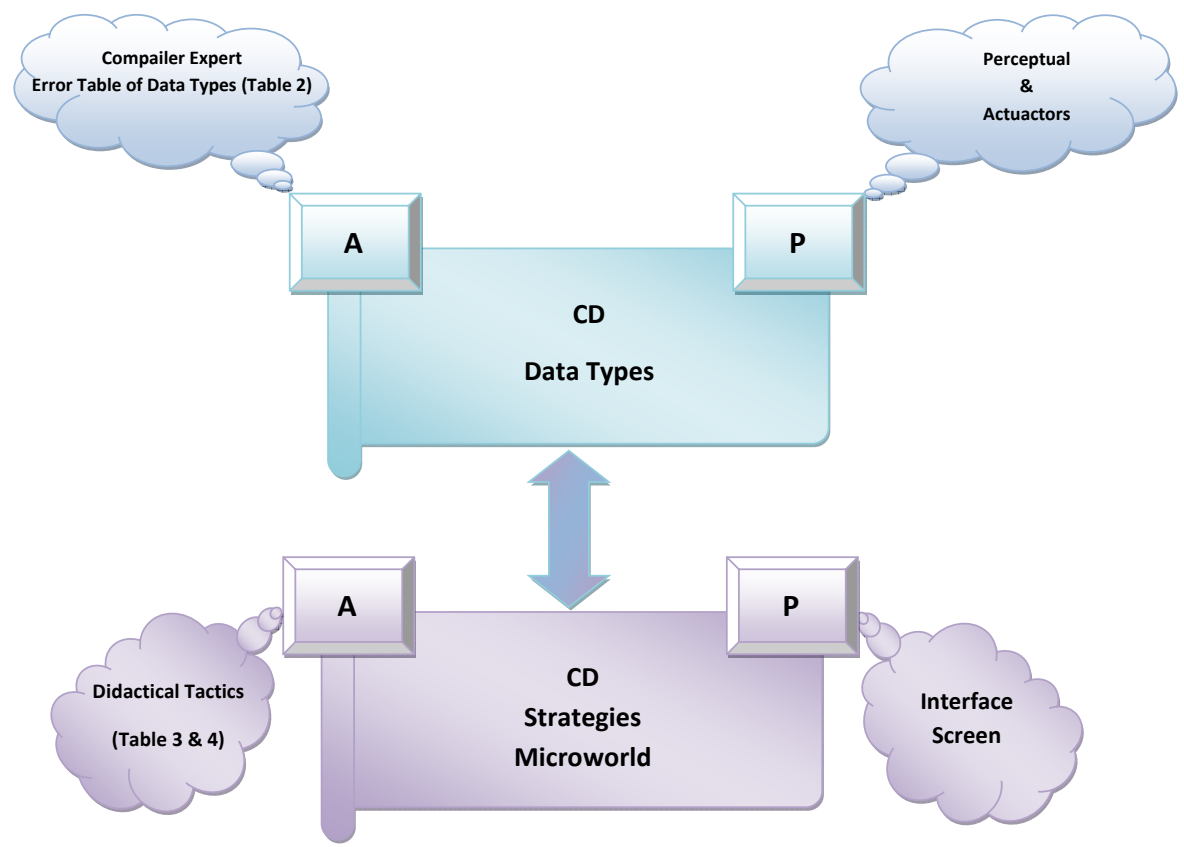

Figure 3.

Representation of the data types agent.

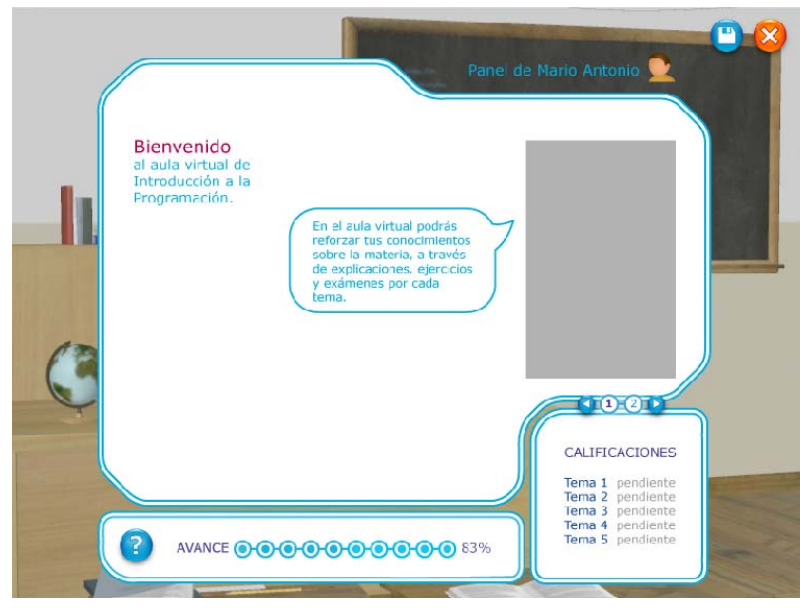

Figure 4.

Screen depecting the scenario presentation.

color combinations for each learning type, taking the type of intelligence which is predominant in the user into account. For more information see Velasco-Santos, Laureano-Cruces, MoraTorres, \& Sánchez-Guerrero, 2009; Honey \& Mumford (1986). In this example, the student is registered (Figure 7) in the system for the first time. Upon conclusion of the registration of his or her personal information, the system assigns a user name and password. Next, the learning styles questionnaire (Alonso, Gallego, \& Honey, 1994) is activated, which is comprised of 80 questions and requires approximately 10 minutes for the student to complete. The system then evaluates the responses and determines the student's learning style (Figure 8). In this case study the student's learning style is theoretical.

The ILS contains a module for evaluation of the internal motivation of the object of study (Mora-Torres et al., 2011), performed through a questionnaire containing eight questions,

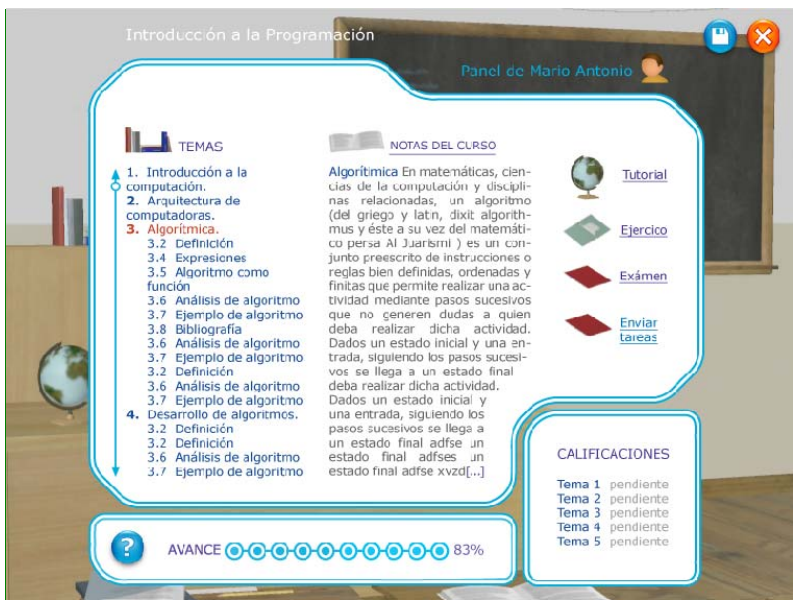

Figure 5.

Screen of the learning object.

which is activated after the system shows the student his or her learning style. Completion of the questionnaire takes approximately five minutes, upon which the system evaluates the responses and determines the student's type of motivation to study. It is worth mentioning that the ILS included Honey and Mumford's definition of internal motivation of the object of study (Honey et al., 1986), who describe the learning styles which they define as: active-they participate in new experiences without prejudices, they have open minds; reflexivethey consider experiences, observe perspective, gather and analyze data before drawing conclusions; theoretical-they adapt and integrate observations to logical and complex theories, they tend to be perfectionists; pragmatic-they apply ideas in a practical manner. This case of example of application will only be relevant when the student has external motivation (Figure 9). 


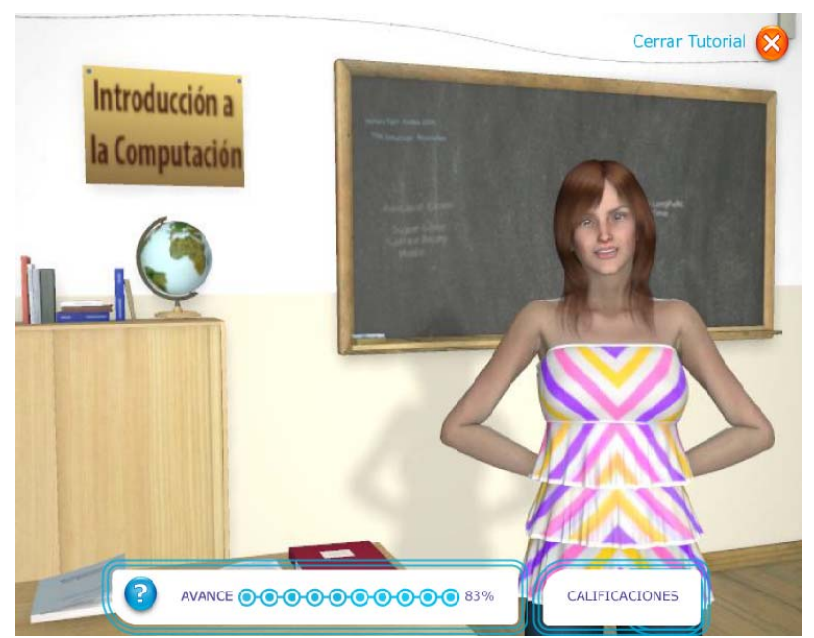

Figure 6.

Screen of the expressions at the pedagogical agent.

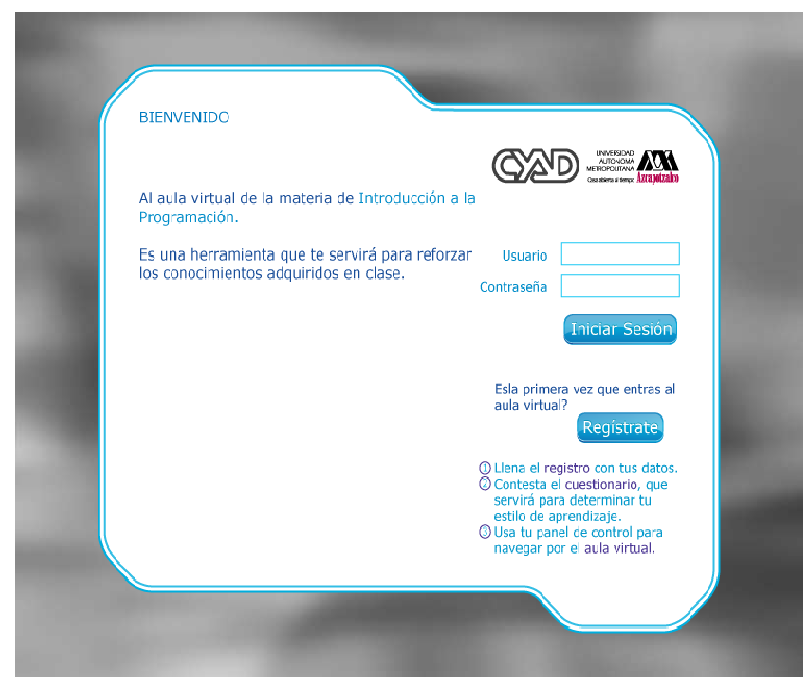

Figure 7.

Screen with the register of the system ProgEst.

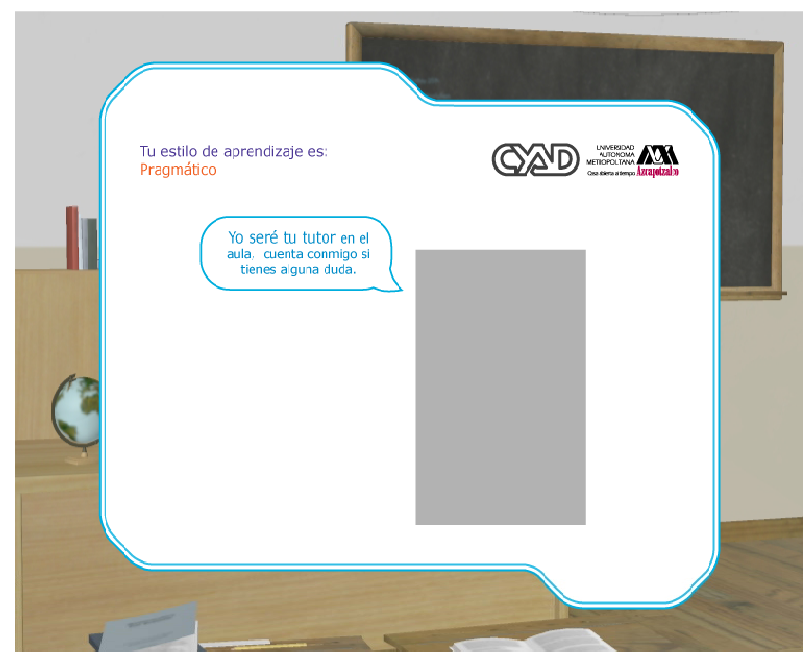

Figure 8.

Screen with the CHAEA questionnaire results.
The data which were generated upon completion of the questionnaires and the record which was assigned are saved in the database for future reference by the ILS. For this case of application, the Data Types exercise was activated in the (LMS) (Learning Management System Moodle, obtained of: http:// moodle.org). As we can see (Figure 10) on the main screen of the data types exercise, the objective is presented to the user and the instructions of the exercise or task to be developed (scenario) are explained. Next, the data types exercise is activated as shown (Figure 11) for the user to complete it.

Upon resolving the exercise, various cases may be presented. Only certain cases of application are described in this section:

- If the student requests help, the system displays the learning object related to the Data Types through the user interface, in accordance with the didactic strategies, the type of motivation to study and the learning style. In this case, the control structure content which is presented is for a student with a theoretical learning style external motivation (Figure 12), so that it will review the data types concepts and then consult. The ILS allows the student to return to the scenario and continue with the exercise, as mentioned in the previous section. The system has the capacity to ask for help within the scenario (exercise), allowing the content of the respective topic to be displayed before asking the Mi- croWorld. This, because of our ILS's trainer approach.

It is noted that interaction are based on a structure that allows an enriched emotional intervention. This through a pedagogical agent (Mora-Torres, Laureano-Cruces, \& Velasco-Santos, 2010). As stated previously the performance of the agents is divided into two subagents, one of which carries out the diagnosis, the objective of which is to observe the environment (comprised of the student's development). Following this observation, evidence is obtained based on the agent's perceptual abilities in order to know if the student uses, does not use or incorrectly uses the skill which is monitored and controlled exclusively by that agent. The error(s) made are detected by means of the observations and the other sub-agent is activated, represented by a MicroWorld, the task of which is to create an environment which helps the student to clarify his or her doubts, all of this through the use of didactic strategies that will guide this intervention until the student is led back to the principal environment, where the error was made.

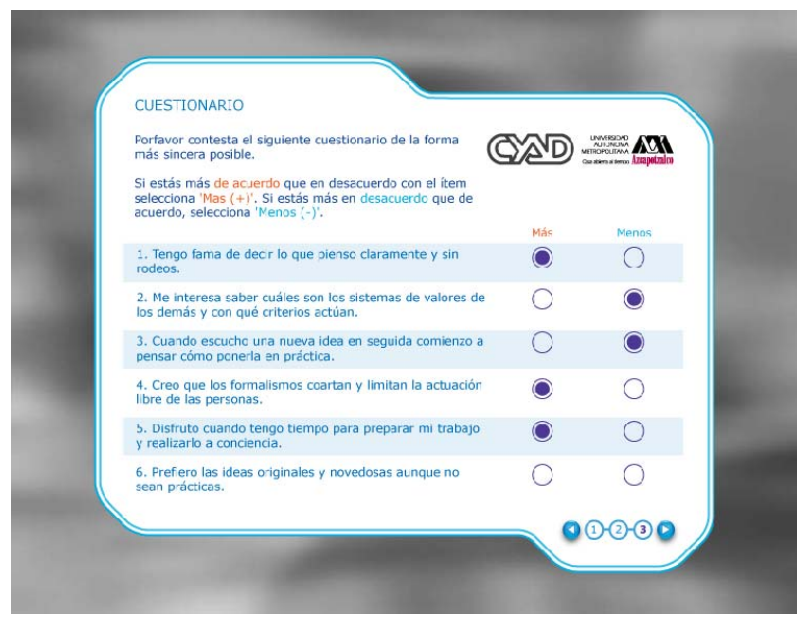

Figure 9.

Screen with the motivation questionnaire. 


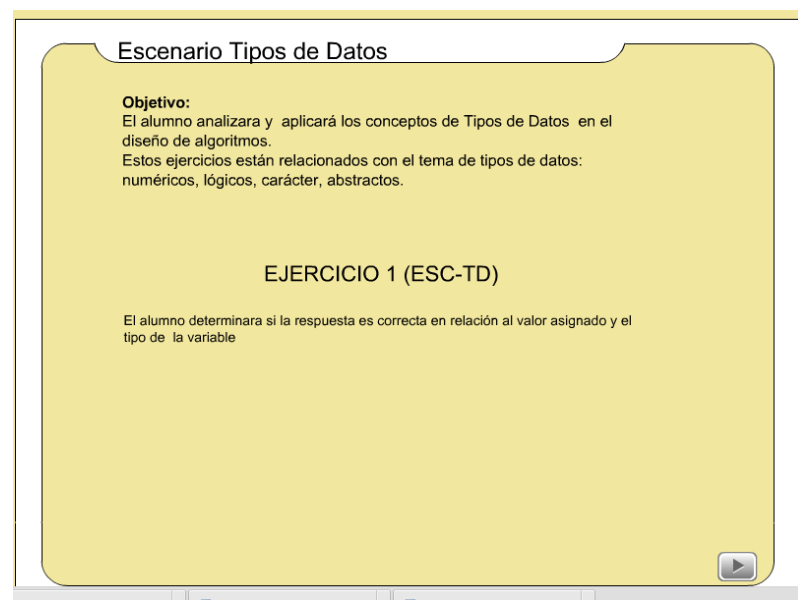

Figure 10.

Principal screen for the exercise of data types agent.

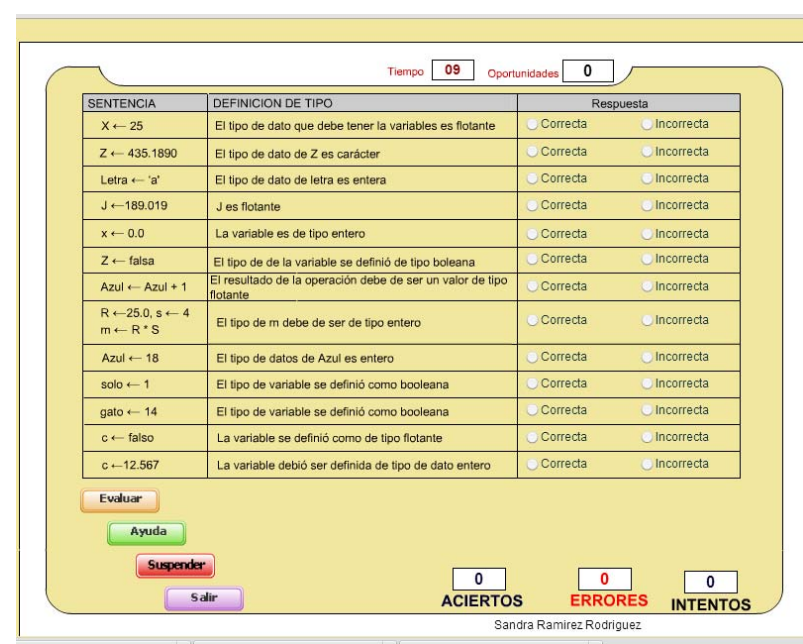

Figure 11.

Screen for the exercise of data types agent.

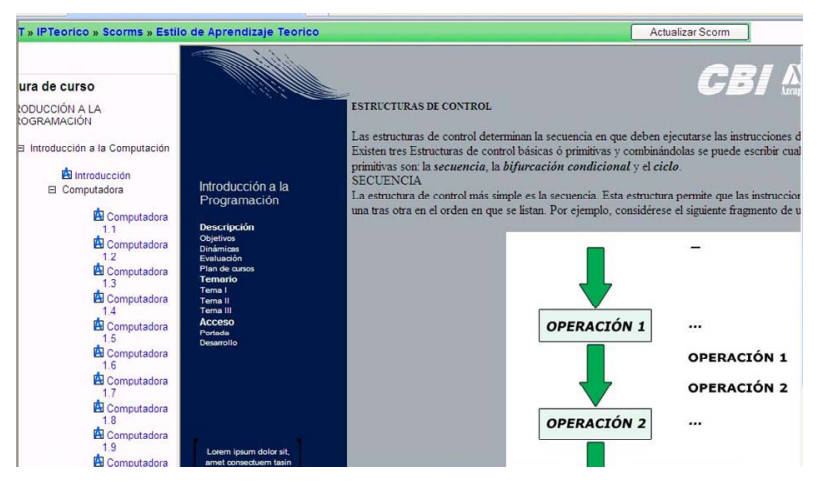

Figure 12.

Screen for the learning object for a student.

For management of errors committed by the student, three types of errors were defined in the ILS: mild $(M)$, serious $(S)$ and fatal $(F)$. This is where ProgEst determines the distinct didactic strategies to apply depending on the type of error. For this case of application we assume that the student commits an error in the exercise (scenario).
For this example, we will apply solely the case of mild errors. Serious errors will be for a student with theoretical type learning with external motivation. For cases where the error is:

1) Mild error (M), imply an overall attention deficit more than a lack of knowledge, that is to say, they possess the specific knowledge and may have used it on previous occasions; nonetheless, due to a lack of attention they become disoriented and fail to complete part of the process. In this case the system verifies which type of learning and motivation the user possesses (external or internal). As the student's learning type is theoretical and he or she is motivated, the system applies the message We can do it together. You must keep trying! as an operational/cognitive strategy, and permits the student to return to the scenario and continue if and when the number of opportunities has not been used up.

2) Serious error (S), imply a significant lack of conceptualization which leads to failure of the data types application (Figure 13). As this case involves a serious error, the ILS solely allows one opportunity to respond to the exercise, verifies if the motivation is internal or external and applies a cognitive operational strategy, displaying the following phrase through the interface: Let's continue. You can do it! It activates the data types learning object thorough the Moodle Learning Management System (LMS), where the student reviews the theoretical information and the control structure application examples.

\section{Testing and Results Analysis}

The ProgEst system was applied to a group of 33 students from the core engineering course at the Universidad Autónoma Metropolitana campus Azcapotzalco. An access code for the system was assigned to each student, each of who completed the questionnaire learning style and internal motivation of the object of study.

As shown in the graph, (Figure 14), 51.52\% of the group of students has a reflexive learning style, $24.24 \%$ is theoretical, $21.21 \%$ is pragmatic and solely $3.03 \%$ is active.

Similarly, we can see in the graph that the internal motivation of the object of study is $42.42 \%$ external motivation, $39.39 \%$ internal motivation and $18.18 \%$ internal-external motivation (Figure 15).

As aforementioned, the system's teaching and learning proc-

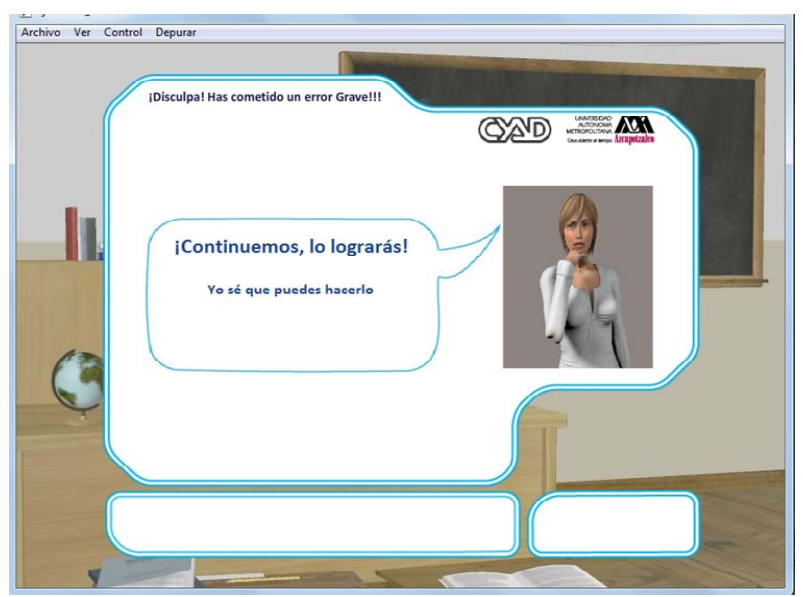

Figure 13.

Screen when the student had a serious error with a theoretical learning style external motivation. 
ess is based on an inference engine inspired in the human tutorial process. Figure 16 presents data on the total student group along with the percentages of the nine elements of the inference engine (Laureano-Cruces et al., 2010a). These elements are connected in a causal matrix which allows us to see the causal interconnection of each element with the others. The learning style was also added to these elements, which will have a direct impact on the interface and internal motivation of the object of study. All of these factors permit selection of the operational strategies in the appropriate moment.

As observed in Figure 16, 100\% show interest and desire to complete the task and solely $36.36 \%$ of the group concluded the task successfully.

We can see in Figure 17 that $60.61 \%$ committed errors. The percentage of students who committed these errors in the first opportunity was $36 \%$ and the system applied a cognitive operative strategy, as it constituted a mild error (see errors in Tables 1 and 2). The Data Types of the LO was activated through the Moodle (LMS) for the purpose of reinforcing the knowledge. It can also be observed in the graph that these students took more time to complete the exercise than had been estimated, which constitutes inactive time, possibly due to the fact that the student did not possess sufficient knowledge to complete the task and the system activated the structured programming material, beginning from the basic programming knowledge, in order to be able a review of the material for the student. Similarly, it can be seen that a very low percentage of $6 \%$, one student, resigned to continue the exercise.

Of the two presented types of errors, the Data Types Agent applied the learning strategies described in Tables 1 and 2 together with the inference engine, in accordance with the aforementioned. As a result, twelve students of the group completed the scenario determined for the Data Types Agent (Figures 16 and 17).

Figure 17 also shows that $36.36 \%$ completed the exercise in the first opportunity, and these students learned $100 \%$ of the material. For the case of students who did not complete the task (because they committed errors or the system interrupted them due to inactive time), and the types of internal motivation of the object of study and the learning style observed in the student, as shown in Figure 18, of the 63\% of students who did not complete the exercise, $29 \%$ are reflexive with external motivation, $14 \%$ are reflexive with internal motivation, $10 \%$ are pragmatic with internal motivation, $9 \%$ are pragmatic with external motivation, $9 \%$ are reflexive with internal-external motivation, $5 \%$ are theorical with external motivation, 5\% are theorical with

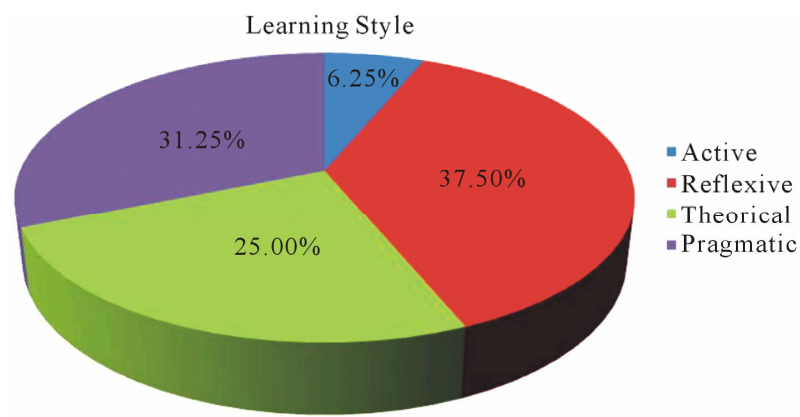

Figure 14.

Learning style.

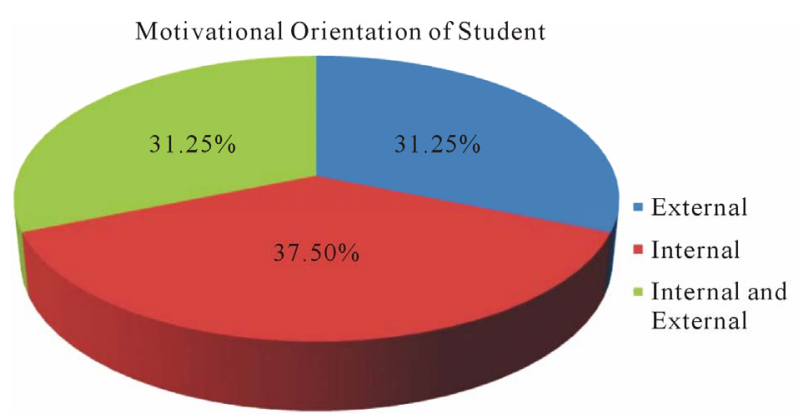

Figure 15.

Motivational orientation of student.

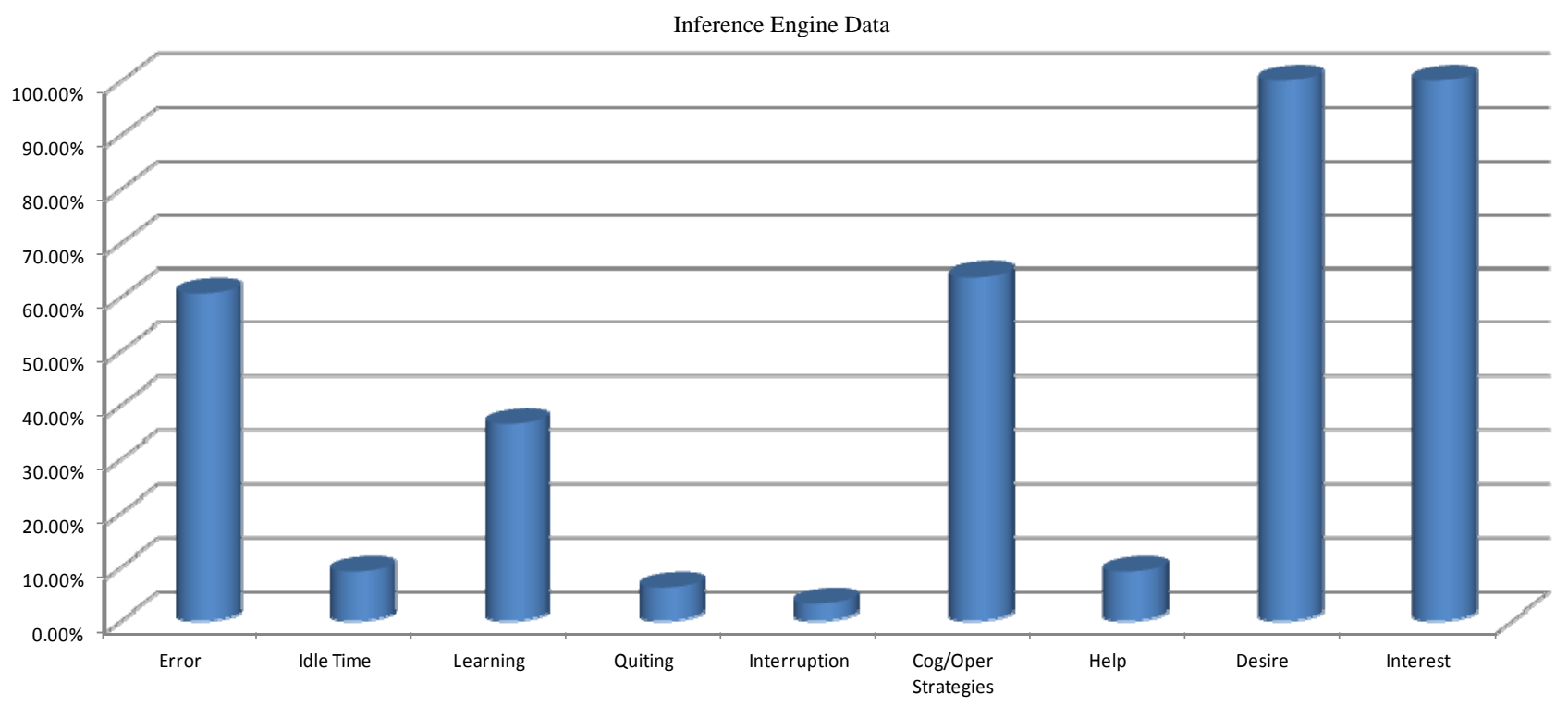

Figure 16.

Inference engine data. 


\section{S.-G. LOURDES ET AL.}

Table 1.

Classification of the didactical tactics and didactical actions to be managed by the diagnostic subagent, applied in ProgEst.

\begin{tabular}{|c|c|c|c|c|}
\hline Event & Objective & $\begin{array}{l}\text { Expressions for Cognitive/Operative } \\
\text { tactics, interruptions and to } \\
\text { ask for help. }\end{array}$ & Actions & Number of Response Opportunities \\
\hline \multirow[t]{2}{*}{ Ask for help (3) } & Internal & $\begin{array}{l}\text { It's a good time to express doubts! } \\
\text { This subject is not so easy. }\end{array}$ & $\begin{array}{l}\text { The expression appears. Next, the } \\
\text { system sends the student to consult } \\
\text { the subject material and permits him } \\
\text { or her to continue with the exercise } \\
\text { after seeking help. }\end{array}$ & $\begin{array}{l}\text { The requests for help are not } \\
\text { limited as long as the student } \\
\text { continues the exercise. }\end{array}$ \\
\hline & External & $\begin{array}{l}\text { ¡Hey Asking for help doesn’t } \\
\text { mean you are not able to do it! }\end{array}$ & $\begin{array}{l}\text { The expression appears. Next, the system } \\
\text { instructs the student to consult the subject } \\
\text { material and permits him or her to continue } \\
\text { with the exercise after seeking help. }\end{array}$ & $\begin{array}{l}\text { The requests for help are not } \\
\text { limited as long as the student } \\
\text { continues the exercise. }\end{array}$ \\
\hline \multirow[b]{2}{*}{ Interruption (5) } & Internal & $\begin{array}{l}\text { Would you like to know } \\
\text { more about this? }\end{array}$ & $\begin{array}{l}\text { Upon pressing the Interruption button, } \\
\text { the exercise is interrupted and the } \\
\text { expression appears. }\end{array}$ & $\begin{array}{l}\text { The requests for help are not } \\
\text { limited as long as the student } \\
\text { continues the exercise. }\end{array}$ \\
\hline & External & Would you like more help? & $\begin{array}{l}\text { Upon pressing the Interruption button, the } \\
\text { exercise is interrupted and the expression } \\
\text { described in the previous column appears. } \\
\text { The student is permitted to continue with } \\
\text { the exercise after seeking help. }\end{array}$ & $\begin{array}{l}\text { The requests for help are not } \\
\text { limited as long as the student contin- } \\
\text { ues the exercise. }\end{array}$ \\
\hline \multirow[t]{4}{*}{ Renunciation (6) } & $\begin{array}{l}\text { Internal and } \\
\text { External }\end{array}$ & $\begin{array}{l}\text { Keep trying! You are } \\
\text { getting closer! }\end{array}$ & $\begin{array}{l}\text { Upon pressing the Exit button, } \\
\text { the exercise ends and the } \\
\text { expression appears. }\end{array}$ & $\begin{array}{l}\text { Upon pressing the button, the system } \\
\text { does not allow the student to return } \\
\text { to the exercise and sends him or } \\
\text { her to the material selected based } \\
\text { on the CHAEA questionnaire. }\end{array}$ \\
\hline & Internal & $\begin{array}{l}\text { You are a winner! Remember } \\
\text { all of your achievements! }\end{array}$ & $\begin{array}{l}\text { Upon correct completion of the } \\
\text { exercise it opens and the student } \\
\text { is shown the expression. }\end{array}$ & \\
\hline & & & & \\
\hline & External & $\begin{array}{l}\text { Success in performing this } \\
\text { exercise demonstrates the } \\
\text { newly acquired skills. }\end{array}$ & $\begin{array}{l}\text { Upon correct completion of the } \\
\text { exercise it opens and the student is } \\
\text { shown the expression. }\end{array}$ & \\
\hline Inactive Period (8) & $\begin{array}{l}\text { Internal and } \\
\text { External }\end{array}$ & Hey! It’s time to get to work! & $\begin{array}{l}\text { After } 30 \text { seconds it opens and the expression } \\
\text { appears. If the student does not respond to } \\
\text { the second inactive period (lasting } 30 \\
\text { seconds) he or she loses one of the } 3 \\
\text { opportunities allowed by the system } \\
\text { to complete the exercise. }\end{array}$ & $\begin{array}{l}\text { The student may request a } \\
\text { maximum of } 3 \text { rest periods. }\end{array}$ \\
\hline
\end{tabular}

Table 2.

Classification of errors based on the didactical tactics and the didactical actions, to be managed by the diagnostic subagent, applied in ProgEst.

\begin{tabular}{|c|c|c|c|c|}
\hline Error (9) & $\begin{array}{c}\text { Internal/External } \\
\text { Objective }\end{array}$ & $\begin{array}{c}\text { Number of Response } \\
\text { Opportunities }\end{array}$ & Actions & Operative/Cognitive Strategy \\
\hline Minor & $\begin{array}{l}\text { Internal and } \\
\text { External }\end{array}$ & $\begin{array}{c}\text { Three } \\
\text { opportunities }\end{array}$ & $\begin{array}{l}\text { Allows the student to return to the } \\
\text { situation and continue, as long as the } \\
\text { maximum number of opportunities } \\
\text { has not been reached. }\end{array}$ & $\begin{array}{l}\text { The following phrase appears: } \\
\text { "We can do it together. You have } \\
\text { to keep trying! }\end{array}$ \\
\hline Fatal & $\begin{array}{l}\text { Internal and } \\
\text { External }\end{array}$ & One opportunity & Exits the exercise. & $\begin{array}{l}\text { The following phrase appears: } \\
\text { "Keep trying, you are getting close" and } \\
\text { sends the student to the domain material } \\
\text { which corresponds to the learning style. }\end{array}$ \\
\hline
\end{tabular}




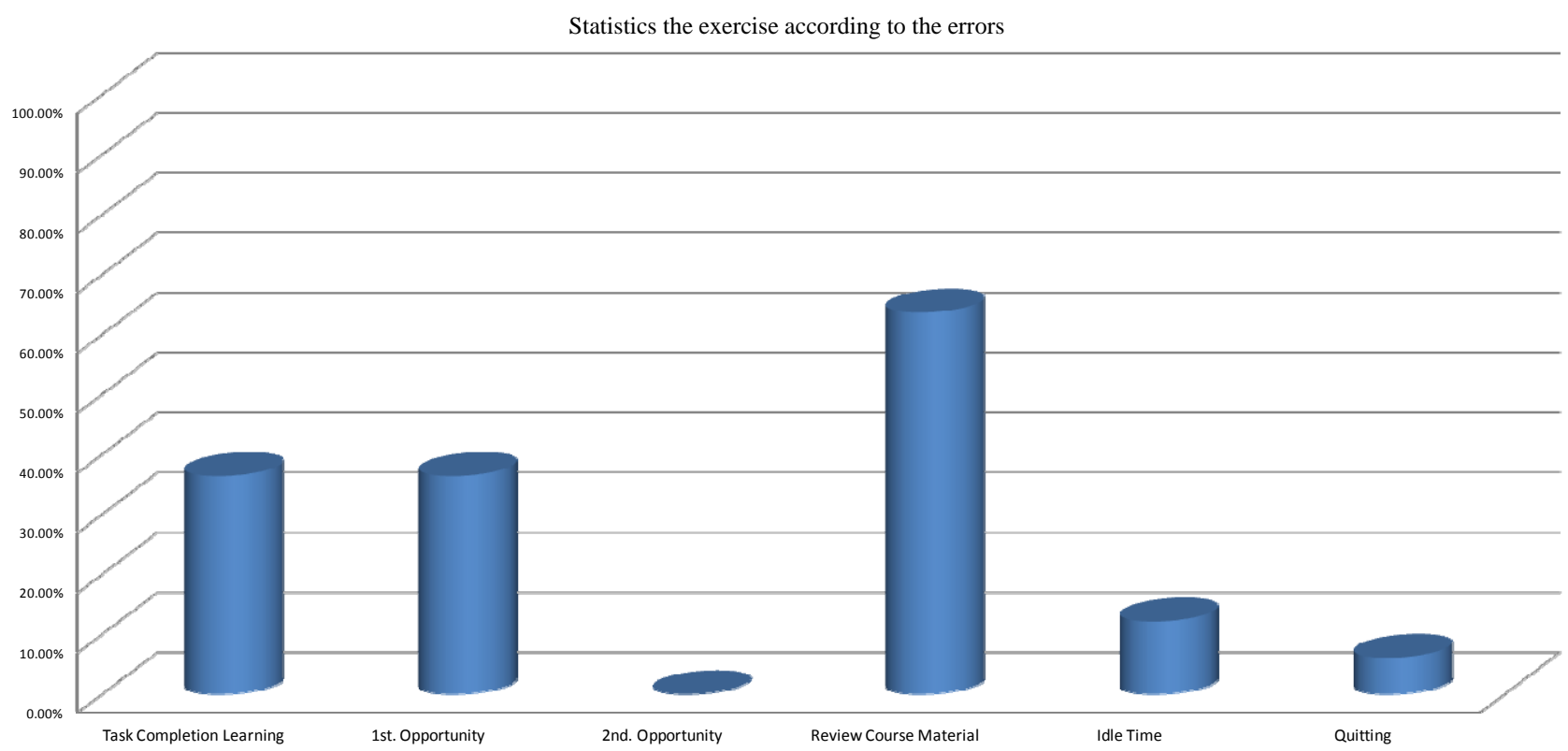

Figure 17.

Statics the exercise according to the errors.

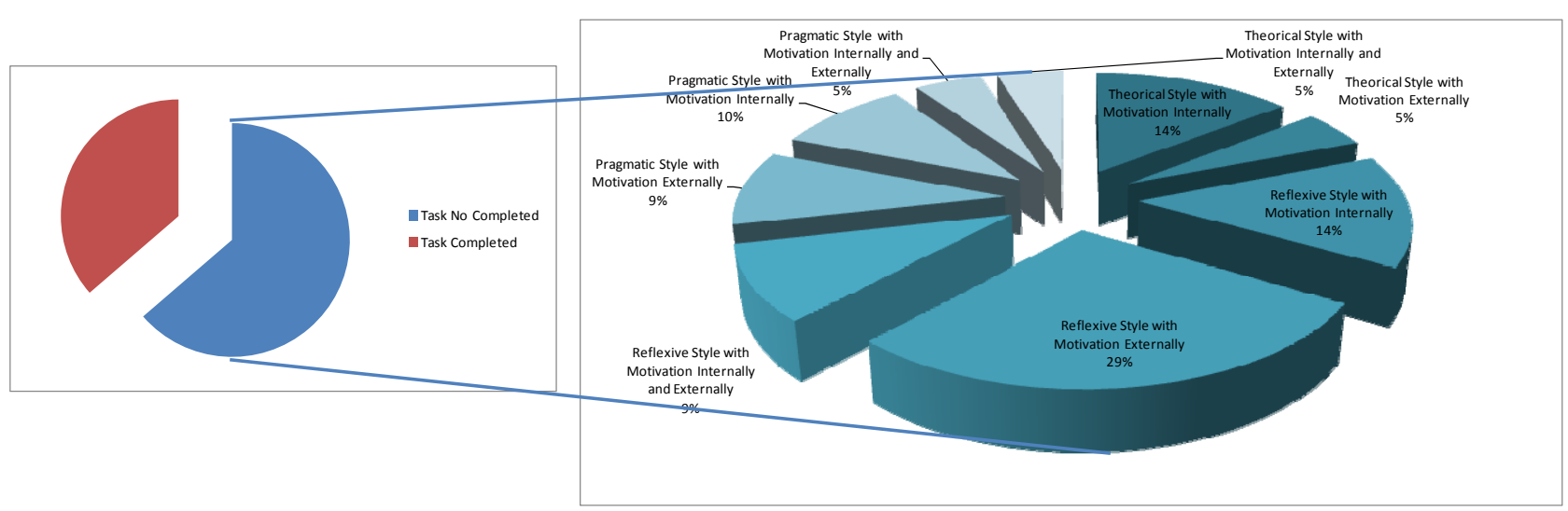

Figure 18.

Students that didn't conclude the exercise.

internal-external motivation and 5\% pragmatic with internalexternal motivation. As aforementioned, this allows us to conclude that the majority of the students with external motivation were eliminated from the application by the system because they failed to respond to the questions in the exercise within the time allowed, possibly due to the fact that they needed more examples of data types applications and exercises to understand the different data types.

\section{Conclusion}

The implementation of AI techinques in the development of the ILS by means of the inference engine permits recommendation of distinct strategies, for the purpose of managing the complexity of the prediction of didactical strategies in order to strengthen the student's teaching and learning process, taking the results of the learning styles and motivational orientation questionnaire into account.

In this system, the implementation of the inference engine based on a general didactics tutor permits: 1) dynamic interaction in the decision-making process in order to select the best educational strategy; 2) predict the possible future status and thus personalize the interactions through the eleven elements which constitute the student model; 3) prevent undesirable states, such as resignation or error, by means of these interactions; and 4) develop a specialized method of handling errors caused by reactive agents. An analysis and design methodology has been created, which may be utilized to develop other ILS's that contain learning objects, through the use of the model designed for the general didactic tutor.

Nonverbal communication plays an important role in our human relationships, as it influences the other person through expressions and transmitted in-formation on the emotional state of the partners. With this in mind it was considered an avatar (in the case study pedagogical agent) as the appropriate interface for ILS-user interaction. The consideration of the avatar (pedagogical agent) is appropriate if the intervention is based on an emotional structure that has been designed according to 
the perceived emotional state of the user.

In order to strengthen the teaching and learning process, the followings are considered:

- Include more specialized subtutors.

- Continue to develop the interface using a pedagogical agent.

\section{Acknowledgements}

This Project is part of the Divisional Project Research Computación Suave y Aplicaciones in the specific line of Intelligent E-Learning, and Formación de Recursos Humanos funded by Universidad Autónoma Metropolitana-Azcapotzalco.

\section{REFERENCES}

Alonso, M. C., Gallego, D. J. and Honey, P. (1994). Los estilos de aprendizaje (Procedimientos de DiagnósICTo y Mejora). Spain: Ediciones Mensajero S.A. Sexta Edicion.

Castaneda, S. (2006). Evaluacion del aprendizaje en el nivel universitario, elaboración de examenes y reactivos-objetivos. UNAM-Psychology Faculty, CONACYT Project 40608-H.

Chan Núñez, M. E., Galeana, de la O. L., \& Ramírez Montoya, M. S. (2006). Objetos de Aprendizaje e Innovación Educativa (pp. 11-44). México: Editorial Trillas.

Honey, P., \& Mumford, A. (1986). Using our learning styles. Berkshire: Peter Honey.

Laureano-Cruces, A., Mora-Torres, M., Ramírez-Rodríguez, J., \& de Arriaga-Gómez, F. (2011). Operative strategies related to an affective-motivational architecture to achieve instructional objectives. Journal Artificial Intelligence Machine Learning/International Congress for Global Science and Technology (ICGST), 11, 15-20.

Laureano-Cruces, A., Mora-Torres, M., Ramirez-Rodriguez, J., de Arriaga-Gómez, F., \& Escarela-Perez, R. (2010a). Cognitive-operative model of intelligent learning systems behavior. Interactive Learning Environments, 18, 11-38. doi:10.1080/10494820802160872

Laureano-Cruces, A., Mora-Torres, M., Ramirez-Rodriguez, J., \& GamboaRodriguez, F. (2010). Implementation of an affective-motivational architecture tied to a teaching-learning process. In J. Sanchez, \& K. Zhang (Eds.), Proceedings of World Conference on E-Learning in Corporate, Government, Healthcare, and Higher Education 2010 (pp. 1930-1938). Chesapeake, VA: AACE. http://www.editlib.org/p/35837.

Laureano-Cruces, A. L., Mora-Torres, M., Ramírez-Rodríguez, J., \& Gamboa-Rodríguez, F. (2009). Emotions as an element that maximizes the effectiveness of a pedagogical agent. In T. Bastiaens et al. (Eds.), Proceedings of World Conference on E-Learning in Corporate, Government, Healthcare, and Higher Education 2009 (pp. 2817-2822). Chesapeake, VA: AACE.

http://www.editlib.org/p/32884

Laureano-Cruces, A., Sánchez-Guerrero, L., Ramirez-Rodriguez, J., \& Mora-Torres, M. (2008a). Learning objects and personalized instruction. In G. Richards (Ed.), Proceedings of World Conference on ELearning in Corporate, Government, Healthcare, and Higher Education 2008 (pp. 1728-1736). Chesapeake, VA: AACE. I

Laureano-Cruces, A., Teran-Gilmore, A., \& Rodriguez-Aguilar, R. M. (2005). Cognitive and affective interaction in a pedagogical agent. ANIEI XVIII National Congress and IV International Congress on Information Processing and Computing, Torreon, 26-28 October 2005. http://delfosis.uam.mx/ ana/
Laureano-Cruces, A., Teran-Gilmore, A., De Arriaga Gomez, F., \& El Alami, M. (2003). La importancia de las estrategias cognitivas en el diseño del curricula didactico (pp. 35-41). ANIEI XVI National Congress and II International Congress on Information Processing and Computing, Zacatecas, 22-24 October 2003.

Laureano-Cruces, A. (2000a). Interaccion dinamica en sistemas de enseñanza inteligentes. Ph.D. Thesis, Institute of Biomedical Studies/UNAM.

http://delfosis.uam.mx/ ana/02_publicaciones/tesis_doctoral/TesisD octoral.PDF

Laureano-Cruces, A., \& de Arriaga-Gómez, F. (2000b). Reactive Agent design for intelligent tutoring systems. Cybernetics and Systems, 31, 1-47. doi:10.1080/019697200124900

Laureano-Cruces, A., \& de Arriaga-Gómez, F. (1998). Multi-agent architecture for intelligent tutoring systems. Interactive Learning Environments, 6, 225-250. doi:10.1076/ilee.6.3.225.3603

Learning Management System Moodle (definition). http://moodle.org

Mora-Torres, M., Laureano-Cruces, A. L., \& Velasco-Santos, P. (2011). Estructura de las Emociones dentro de un proceso de enseñanzaaprendizaje. Perfiles Educativos-UNAM, 33, 64-79.

Mora-Torres, M., Laureano Cruces, A., \& Velasco-Santos P. (2010). Estructura de las emociones dentro de un proceso de enseñanzaaprendizaje. Revista Indexada "Perfiles Educativos", 33.

Muñoz-Arteaga, J., Osorio-Urrutia, B., Álvarez-Rodríguez, F., \& Cardona-Salas, P. (2008). Methodology for creating learning objects and integrating them into a learning management system. Universidad Autónoma de Aguascalientes, Distrito Federal, México

Pintrich, P., Smith, D., García, T., \& Mckeachie, W. (1991). A manual for the use of the motivated strategies for learning questionarie (MSQL). Michigan, USA: National Center for Research to Improve Postsecondary Teaching and Learning University of Michigan.

Reilly, R. R., \& Lewis, E. L. (1991). Educational psychology application for classroom, learning and introduction. New York, Maxwell McMillan International.

Sanchez-Guerrero, L., Laureano-Cruces, A. L., Mora-Torres, M., \& Ramirez-Rodriguez, J. (2011). Multiagent architecture for errors management in content organized in learning objects. Proceedings of World Conference on E-Learning in Corporate, Government, Healthcare, and Higher Education 2011 (pp. 2462-2467). Chesapeake, VA: AACE.

Sanchez-Guerrero, L., Laureano-Cruces, A. L., Mora-Torres, M., \& Ramírez-Rodríguez, J. (2010). Scenarios in application of cognitive didactics for an Intelligent Learning System (relation with the types of errors). Proceedings of World Conference on E-Learning in Corporate, Government, Healthcare, and Higher Education 2010 (pp. 322-327). Chesapeake, VA: AACE. http://www.editlib.org/p/35561

Sanchez-Guerrero, L., Laureano-Cruces, A., Mora-Torres, M., \& Ramirez-Rodriguez, J. (2009). An intelligent learning system within a learning object. Proceedings of World Conference on E-Learning in Corporate, Government, Healthcare, and Higher Education 2009 (pp. 1917-1926). Chesapeake, VA: AACE. http://www.editlib.org/p/32742

Velasco Santos, P., Laureano Cruces, A., Mora Torres, M., \& Sánchez Guerrero, L. (2009). Un diseño de interfaz tomando en cuenta el estilo de aprendizaje (pp. 311-320). 22nd National Congress and 8th International Congress on Information Processing and Computing, Ensenada, 21-23 October 2009.

Velasco-Santos, P., Laureano-Cruces, A., Mora-Torres, M., \& SánchezGuerrero, L. (2008). La Importancia del diseño de una Interfaz en el proceso enseñanza-aprendizaje (pp. 108-113). ANIEI XXI National Congress and VII International Congress on Information Processing and Computing, Monterrey, 1-3 October 2008. 